\title{
Building Ultra-Thin Layers by Ceramic Laser Sintering
}

\author{
Hwa-Hsing Tang* \\ Department of Mechanical Engineering, National Taipei University of Technology, Taipei 10608, Taiwan, R. O. China
}

The layer thicknesses of rapid prototyping 3D parts must be minimized to reduce the dimensional tolerance and improve the surface roughness. This paper studies the thinnest layer feasible by Ceramic Laser Sintering (CLS) and analyzes the reasons why ultra-thin layers could be built with CLS.

Manufacturing a work piece with a proper scanning parameter $(3200 \mathrm{~mm} / \mathrm{s}$ scanning speed, $33 \mathrm{~W}$ laser power) verified a 20 -layer square work piece could be made successfully with $0.015 \mathrm{~mm}$ layer thickness, which is the thinnest layer made by a powder-based process.

Regarding the feasible layer thickness, effects of the following four significant influential parameters were discussed: (1) powder particle size, (2) paving force carrying capacity of paved layer, (3) upward deformation of the property transformation zone, and (4) anti-fracture strength of the property transformation zone.

The reasons why CLS could build ultra-thin layers were: (1) layers were built with slurry; (2) the inherent solid green support could withstand the paving force and prevent excessive upward deformation; (3) the lowest working temperature was decreased from $1800^{\circ} \mathrm{C}$ of Ceramic Laser Fusion to $1200^{\circ} \mathrm{C}$.

(Received October 24, 2005; Accepted January 20, 2006; Published March 15, 2006)

Keywords: rapid prototyping, ceramic laser sintering, ultra-thin layers, powder-based process

\section{Introduction}

As the rapid prototyping (RP) technology has evolved from RP into rapid tooling (RT), the demand for higher precision and less surface roughness has increased. For instance, to fulfill the quality demand of precision casting RP products must maintain their dimensional tolerance within $\pm 0.5 \%$, and their surface roughness, $\mathrm{Rq}$, should be no greater than $3 \mu \mathrm{m} .{ }^{1)}$

Rapid prototyping is characterized by stacking layers for building 3D parts. Thus layer thickness must be minimized so that the dimensional tolerance of the part can be reduced and the surface roughness can be improved. For example, by reducing the layer thickness to $13 \mu \mathrm{m}$, a surface roughness less than $3 \mu \mathrm{m}$ may be obtained. ${ }^{2)}$ Most of the existing commercial RP processes and systems such as Selective Laser Sintering (SLS), Stereolithography Apparatus (SLA), Three Dimensional Printing (3DP), Fused Deposition Modeling (FDM) can not build layers with $13 \mu \mathrm{m}$ thickness. Therefore, it is critical for RP technology to build thinner layers so that more accurate RP parts can obtain extensive acceptance in industry and compete with the conventional precision casting and even with NC machining.

Table 1 , based on a literature survey, ${ }^{3-5)}$ compares the minimum layer thicknesses employed in existing processes. Two factors influence the layer thickness: paving method and material type. The mostly applicable paving methods are binding, spraying, and scraping, while the most common material types are sheet, liquid, and powder.

The binding method controls layer thickness by setting sheet material thickness. The spraying method provides an approximate layer thickness by controlling the parameters of nozzle spraying or squeezing, and develops an accurate layer thickness only after a milling process. The scraping method provides a definite layer thickness by scraping, thereby exerting a paving force on the underneath layers, which must

*Corresponding author, E-mail: hhtang@ntut.edu.tw
Table 1 Comparison of minimum layer thickness employed in existing processes.

\begin{tabular}{llll}
\hline $\begin{array}{c}\text { Binding } \\
\text { method }\end{array}$ & $\begin{array}{c}\text { Spraying } \\
\text { method }\end{array}$ & \multicolumn{2}{c}{ Scraping method } \\
\hline Sheet material & Liquid-Based & Liquid-Based & Powder-Based \\
\hline LOM & OBJET & Meiko & SLS(2000) \\
$(1015)$ & $\left(\right.$ Eden $\left.330^{\mathrm{TM}}\right)$ & $($ LC-315) & Sinterstation \\
$: 0.05 \mathrm{~mm}$ & $: 0.016 \mathrm{~mm}$ & $: 0.01 \mathrm{~mm}$ & System \\
& & & $: 0.076 \mathrm{~mm}$ \\
\hline KINEGY & Solidscape & SLA & EOS \\
$($ Zippy I) & $($ T612 & $($ Viper $)$ & (M250 \\
$: 0.05 \mathrm{~mm}$ & Benchtop) & $: 0.02 \mathrm{~mm}$ & Xtended) \\
& $: 0.013 \mathrm{~mm}$ & & $: 0.02 \mathrm{~mm}$ \\
\hline & FDM & SOUP & Z-Corp \\
& (Prodigy, & $(2500 \mathrm{~F})$ & $(310)$ \\
& Vantage) & $: 0.025 \mathrm{~mm}$ & $: 0.076 \mathrm{~mm}$ \\
& $: 0.178 \mathrm{~mm}$ & & \\
\hline & & & MCP(REALI \\
& & & - ZER) \\
& & & $: 0.05 \mathrm{~mm}$ \\
\hline
\end{tabular}

be supported firmly to avoid damage.

Since the thinnest sheet is about $0.05 \mathrm{~mm}$, the smallest layer thickness is limited to be $0.05 \mathrm{~mm}$. Liquid materials can have a particle size less than $100 \mathrm{~nm}$, and they can be sprayed by a nozzle to form a layer of any small thickness. During spraying no force is applied on the paved part, but if the thickness of the applied liquid layer will be controlled by a scraper, solid support for the overhanging structure is necessary to resist the scraping force. So far, the thinnest liquid layer thickness, $0.01 \mathrm{~mm}$, has been produced by Meiko (LC-315). ${ }^{4)}$

Powder material is, up to now, difficult to be paved to form layers as thin as $0.01 \mathrm{~mm}$ because of the limitations of the treatable grain size. Thus a layer thickness of $0.07 \mathrm{~mm}$ is the lower limit for many processes such as SLS of 3D Systems or 3DP of the Z Corporation. Selective Laser Melting (SLM) of MCP can pave $0.05 \mathrm{~mm}$ thickness layers. ${ }^{5)}$ Shellabear has 


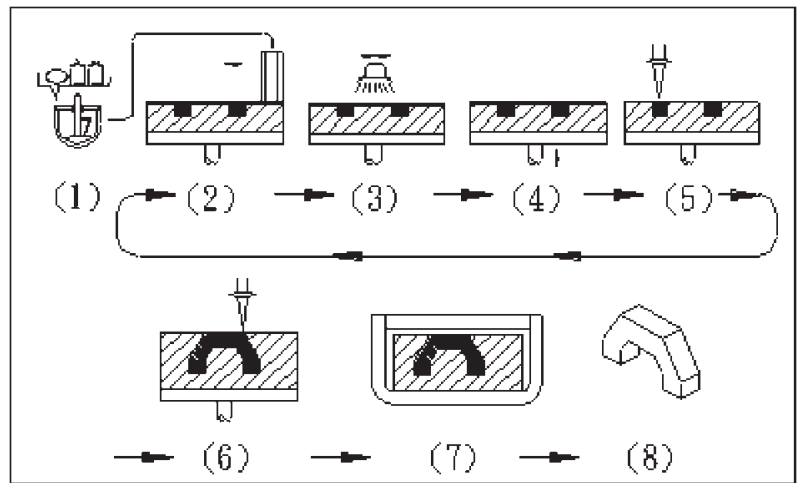

Fig. 1 Process of ceramic laser fusion.

reported that M 250 Xtended of EOS GmbH is able to make parts with $0.02 \mathrm{~mm}$ layer thickness. ${ }^{3)}$ Compared with parts laid up by layer with $0.05 \mathrm{~mm}$ thickness, a part made by layers with only $0.02 \mathrm{~mm}$ thickness shows significantly improvements in surface roughness and resolution of fine details.

Powder material is superior to liquid materials in terms of the available material type because powders can be plastic, metal, or ceramic, and they can be used directly to make plastic, metal or ceramic parts; whereas most of liquid materials are photo resin, which can be used directly to make plastic parts only. However, the above-mentioned several commercial powder-based systems are not able to pave a layer thinner than $0.013 \mathrm{~mm}$ to meet the requirements of precision casting industry. Therefore, it is necessary to develop new RP processes and systems for paving ultra-thin thickness layers from powder material. A new RP process, called Ceramic Laser Fusion (CLF) and patented by this author, ${ }^{6-9)}$ may have potential to achieve this objective.

The process (see Fig. 1) begins by mixing an inorganic binder such as volcanic clay and a dissolving agent with ceramic powder such as Silicon Oxide to form slurry. Using a scraping method, a definite fine slurry layer can be formed, which is preferably dried and hardened by heating. Applying a laser to the ceramic green part, a melted property transformation zone, which cannot be etched by Sodium Hydroxide water solution, is formed. The non-scanned green portion of the dried layer becomes the support for the work piece. The solid green portion supports the 3D work piece and prevents it from deformation. After paving and drying repeatedly, the solid green support and the 3D work piece grow together to form an integrated block. When the finished block is immersed in Sodium Hydroxide water solution, the green support will be etched, and removed from the work piece, leaving no breaking marks. Since this process uses a slurry type material for layer paving, in which ceramic powder of the finest grain size can be used, it can make work pieces with ultra-thin layers. But the thinnest layer yet made by this process is $0.1 \mathrm{~mm},{ }^{9)}$ and there has been no research on minimizing the layer thickness.

This paper presents a modified process, Ceramic Laser Sintering (CLS), in which volcanic clay is melted instead of melting ceramic powder in CLF. The ceramic powder in solid state will be connected by liquid volcanic clay. The

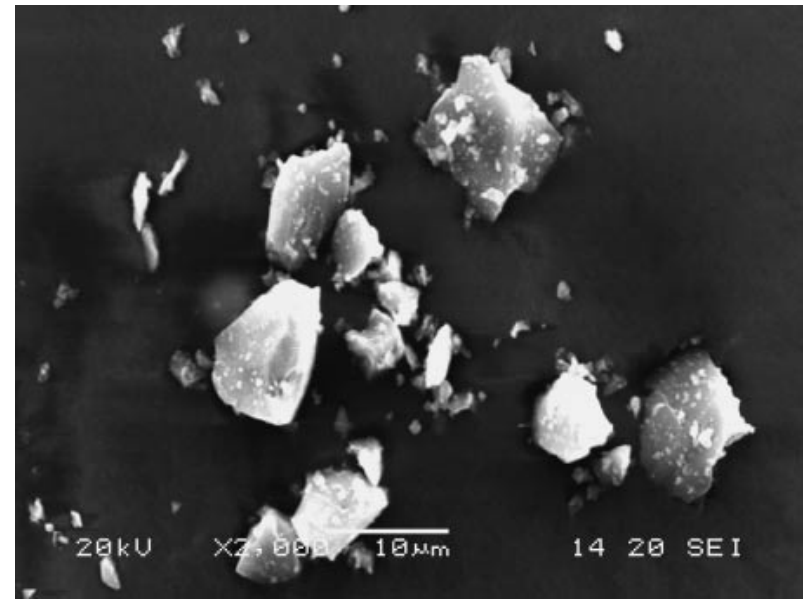

Fig. 2 Topography of silica powder under SEM.

purpose of this modification is so that the deformation of the property transformation zone can be reduced by lowering the working temperature, and thinner layer can be made more easily.

This paper is to study the feasible thinnest layer built by CLS and analyzes the factors affecting the capability to build ultra-thin layers with CLS. The thinnest layer achieved by CLS is verified by a series of experiments.

\section{Experiments}

\subsection{Material}

The material used was a mixture of 64 mass $\%$ silica, 24 mass $\%$ water, 10 mass $\%$ silica sol, and 2 mass $\%$ volcanic clay (VOLCLAY SPV-200). The silica contained $99.2 \%$ $\mathrm{SiO}_{2}$ (min); SEM photography shown in Fig. 2 indicates the irregular shape of silica grains, all with several sharp angles, and with grain sizes mostly smaller than $10 \mu \mathrm{m}$. The binders were volcanic clay and silica sol containing 40 mass $\% \mathrm{SiO}_{2}$ and 60 mass $\%$ water.

\subsection{Equipment for fabrication}

A series of experiments were conducted using two selfdeveloped RP Systems: the Plotter System and the Scanner System. The Plotter System includes a paving device, a drying device, an $\mathrm{X}-\mathrm{Y}$ plotter with a $50 \mathrm{~W} \mathrm{CO}_{2}$ laser source, and a $\mathrm{Z}$-axis working platform. This System is fully automatic; its process computer can control manufacturing procedures such as paving, drying, and laser scanning, as well as raising and lowering the working platform. This system can manufacture large complex work pieces. Due to the precision limitations of the $Z$ axis (about $\pm 5 \mu \mathrm{m}$ ) and the restriction of scanning speed (lower than $300 \mathrm{~mm} / \mathrm{s}$ in vector scan and lower than $1000 \mathrm{~mm} / \mathrm{s}$ in raster scan), only preliminary experiments were conducted by this system. Due to the demand for dimensional precision and fast scanning speed during ultra-thin layer making, the relevant single layer and multi layer experiments with ultra-thin layers could only be conducted by the Scanner System. The Scanner System included a paving device, a drying device, a scan head with a $50 \mathrm{~W} \mathrm{CO}_{2}$ laser source, and a $\mathrm{Z}$-axis elevating platform. The scan head had two galvanometer scanners with 


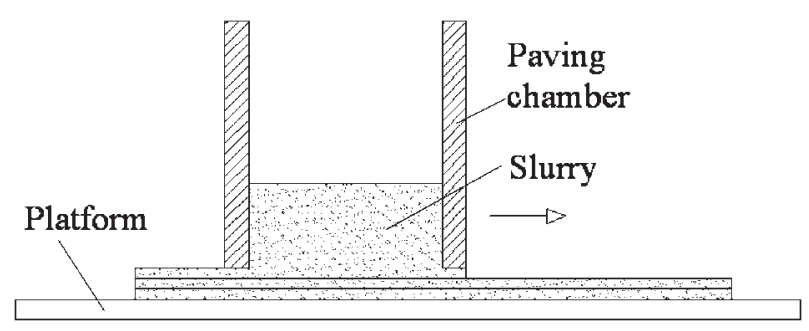

Fig. 3 Schematic of CLF paving device.

fast scanner speed (up to $11,500 \mathrm{~mm} / \mathrm{s}$ ) and the $Z$-axis working platform had high resolution (about $\pm 1 \mu \mathrm{m}$ ). The Scanner System was not fully automatic, and it could conduct only basic experiments such as parts with identical cross sections.

\subsection{Procedures of experiments}

\subsubsection{Paving experiments}

This experiment was to determine the thinnest layers that can be paved on the Plotter System and the Scanner System. Figure 3 is the schematic of the paving device, which is similar to the principle of the Doctor Blade. ${ }^{10)}$ The speed of paving chamber and the descending distance of working platform are the two major paving parameters.

First, several layers with different thickness were paved by the Plotter System. The speeds of paving chamber were set to be a geometric series with a common ratio of 1.3. They were $13,17,23,30,39,51,66,86,110,143$, and $186 \mathrm{~mm} / \mathrm{s}$ respectively. The descending distance of the working platform determined the layer thickness. This experiment set five descending distances of $0.15,0.1,0.05,0.025$, and $0.01 \mathrm{~mm}$ respectively. The paved green layers were dried by an infrared dryer. According to visual inspection of the paved green layers the suitable paving speed and feasible thinnest thickness could be determined.

In addition, layers with different thickness were also paved on the Scanner System. The paving action on this system must be made manually. The setting of descending distances was $0.15,0.1,0.05,0.04,0.030,0.02,0.015$, and $0.01 \mathrm{~mm}$.

\subsubsection{Laser scanning experiments}

The foundation of the laser scanning is based on line scanning. Figure 4 shows laser scanning parameters; a line overlaps another line, and multiple overlapped lines make up a layer; one layer overlaps another layer, and multiple overlapped layers make up a 3D body. Therefore, the laser scanning procedure can be classified into three categories: 1) line scanning, 2) multiple line scanning (layer scanning), and 3) multiple layer scanning (body scanning).

The input parameters of line scanning are laser power $\left(P_{\mathrm{L}}\right)$ and scanning speed $\left(V_{\mathrm{s}}\right)$; the results are line width $\left(W_{\mathrm{L}}\right)$ and line depth $\left(D_{\mathrm{L}}\right)$. During layer scanning an additional input parameter scanning space $\left(S_{\mathrm{S}}\right)$ and line width $\left(W_{\mathrm{L}}\right)$ form the ratio of width overlap $\left(R W_{\mathrm{o}}\right)$.

$$
R W_{\mathrm{o}}=\left(W_{\mathrm{L}}-S_{\mathrm{s}}\right) / W_{\mathrm{L}}=W_{\mathrm{o}} / W_{\mathrm{L}}
$$

The results of the layer scanning are layer width and layer depth $\left(D_{\text {Layer }}\right)$. During body scanning, the additional input parameter of layer thickness $\left(D_{n}\right)$ together with layer depth $\left(D_{\text {Layer }}\right)$ form the ratio of depth overlap $R D_{\text {oLayer }}$ :

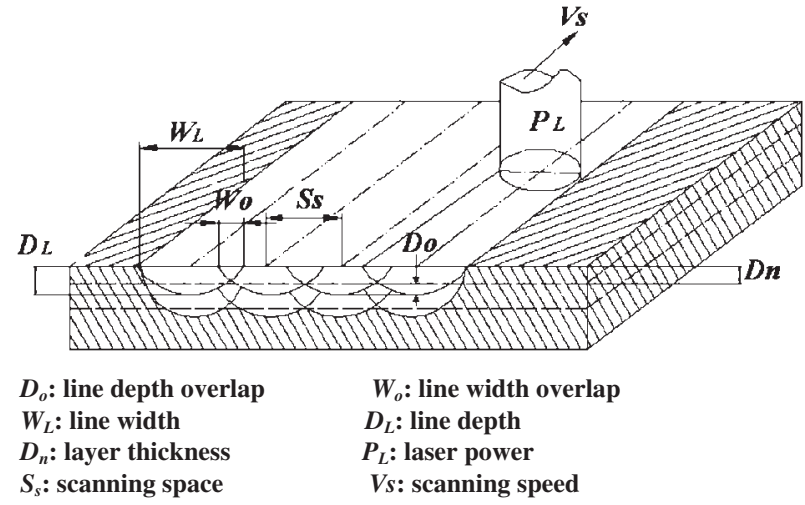

Fig. 4 Laser scanning parameters.

$$
R D_{\text {oLayer }}=\left(D_{\text {Layer }}-D_{n}\right) / D_{\text {Layer }}=D_{\text {oLayer }} / D_{\text {Layer }}
$$

The results of body scanning are body width and body depth.

Building a RP work piece with ultra-thin layers needs relatively low laser energy density; e.g. using $0.17 \mathrm{~J} / \mathrm{mm}^{2}$ is suitable to build a layer with $0.08 \mathrm{~mm}$ thickness. Thus the part's average temperature will not be raised significantly during the laser scanning, and so it is reasonable to assume that temperature variation can be neglected and the initial temperature of the work piece during each scanning operation is the same. Therefore, if laser power and scanning speed are kept constant, the line width and the line depth of the property transformation zone remain constant, no matter where the location is and what the scanning sequence is. Consequently, the line depth must be equal to layer depth and the line depth overlap ratio must be equal to the layer overlap ratio.

$$
R D_{\text {oLayer }}=R D_{\mathrm{o}}=\left(D_{\mathrm{L}}-D_{n}\right) / D_{\mathrm{L}}=D_{\mathrm{o}} / D_{\mathrm{L}}
$$

Therefore, if line width, line depth, and the ratios of line width overlap and line depth overlap are all known, the body's dimensions can be determined. As a result, there are only four scanning parameters: laser power, scanning speed, scanning space or line width overlap ratio, and layer thickness or line depth overlap ratio.

\section{(1) Experiment with laser line scanning}

The two major input parameters of laser line scanning, laser power $\left(P_{\mathrm{L}}\right)$ and scanning speed $\left(V_{\mathrm{s}}\right)$, can be varied to make either a high temperature scanning or a low temperature scanning. The high temperature scanning uses a high laser power density and a low scanning speed to irradiate the dried green layer and to elevate its temperature to a temperature over the melting point of silica (corresponding to scanning operation of CLF). In contrast, the low temperature scanning uses a low laser power density and a high scanning speed to heat the dried green layer and to elevate its temperature to a temperature below the melting point of silica but higher than the melting point of volcanic clay (corresponding to scanning operation of CLS). The line width and line depth under the high temperature scanning are greater than those under the low temperature scanning. Because the objective of this study is thin layer making, more attention must be paid to low temperature scanning.

The Plotter System is only suitable for paving layers 
thicker than $0.03 \mathrm{~mm}$ because the accuracy of $Z$-axis is low (about $\pm 5 \mu \mathrm{m}$ ) and its vector scanning speed is limited to $300 \mathrm{~mm} / \mathrm{s}$, which is not fast enough for building ultra-thin layers. On the contrary, the Scanner System can pave layers thinner than $30 \mu \mathrm{m}$ because of its accurate $Z$-axis (about $\pm 1 \mu \mathrm{m})$ and its fast vector scanning speed $(11,500 \mathrm{~mm} / \mathrm{s})$. Consequently, the experiments for determining the thinnest layer thickness were conducted on this system. For both Plotter System and Scanner System the laser powers were set to be constant, 30 and $33 \mathrm{~W}$ respectively. Increasing the laser scanning speed, the line width and line depth would be decreased. On the Plotter System, experiments with scanning speeds lower than $300 \mathrm{~mm} / \mathrm{s}$ were conducted. On the Scanner System, experiments with a set of 7 scanning speeds higher than $300 \mathrm{~mm} / \mathrm{s}(650,800,1000,1300,1600,2400$, and $3200 \mathrm{~mm} / \mathrm{s}$ ) were conducted. After scanning, each specimen was removed and adhered to specimen holders to measure the line widths and line depths by a Mitutoyo tool microscope.

\section{(2) Determining the ratio of line width overlap and the} ratio of line depth overlap

With the line widths and line depths obtained from the laser line scanning experiments, layers can be built if a proper line width overlap ratio is applied. Layers can be connected each other to build a three dimensional object if a proper ratio of layer depth overlap (or ratio of line depth overlap) is applied. Larger overlap ratio leads to a stronger connection between lines or between layers and the produced layer thickness will be more homogeneous. However, it also leads to increased deformation because there is more energy absorbed by the work piece, and scanning time is extended. Smaller overlap ratio leads to a weaker connection between lines or between layers, and the resulting layer thickness will be less uniform; but it will reduce deformation because there is less energy absorbed by the work piece and the scanning time is shorter. Therefore, the proper overlap ratio depends on the intended application for the work piece. The overlap ratio can neither be too large nor too small in order to guarantee a proper connection and a minimized deformation.

In this paper an approximately $33 \%$ overlap ratio was used for multi-layer experiments. According to the definition of the ratio of line depth overlap, the scanning pattern of three different ratios of line depth overlap, 50, 33, and 20\%, are shown in Fig. 5. The property transformation zone depths of these ratios are 2 times, 1.5 times, and 1.25 times the layer thickness, respectively. The ratio of line depth overlap must be larger than 1 so that there is a connection between layers. Since there is a weaker connection results from the smaller overlap area, and considering the process error and mechanical error of the $Z$-axis, a large line depth overlap ratio is preferred. But the property transformation zone should not be deeper than two times the layer thickness (corresponding to $50 \%$ ratio of line depth overlap); otherwise the produced smallest feature must be larger than two times the layer thickness and the real layer thickness will be larger than two times the paved layer thickness. The ratio of line depth overlap used in this paper was based on the experimental results from $\mathrm{Su}{ }^{11)}$ If the ratio of line depth overlap was over $46.8 \%$, the samples absorbed a large amount of energy and the deformed property transformation zones were damaged by the scraper during the paving operation. Once the ratios of

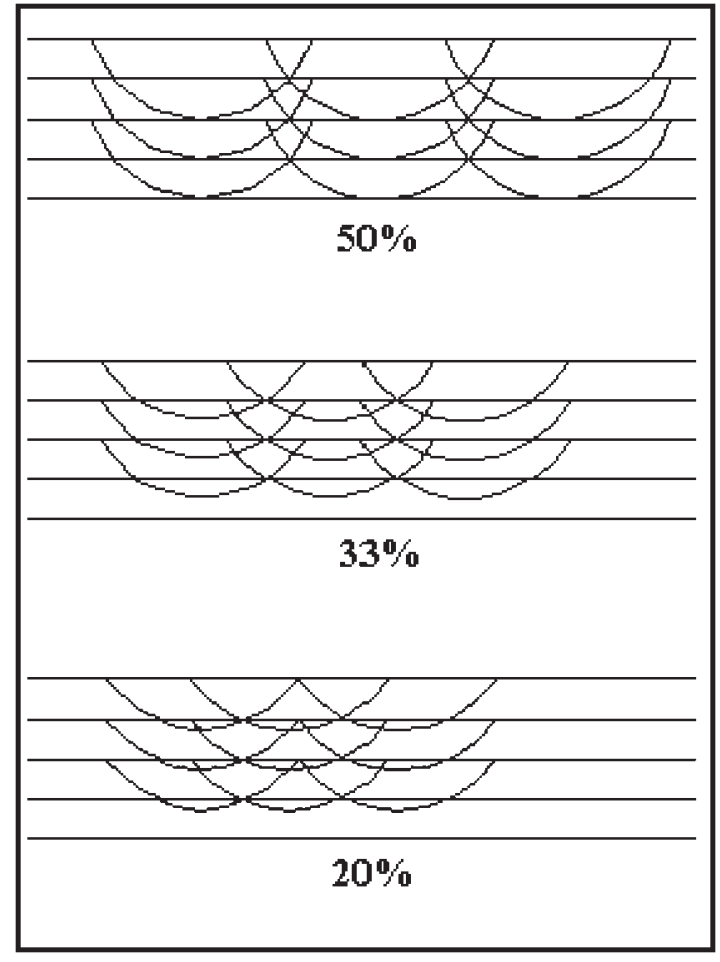

Fig. 5 Ratio of line depth overlap.

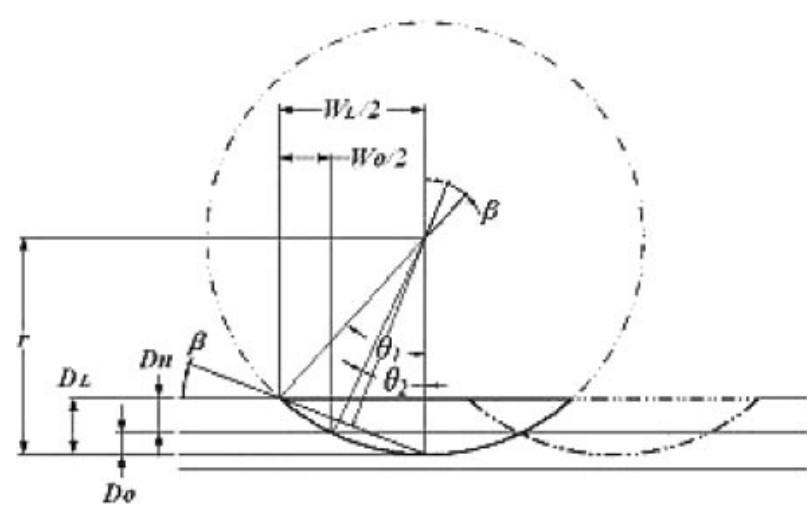

Fig. 6 Determining ideal ratio of line width overlap.

line depth overlap were reduced to $35.9,27$, or $18.7 \%$, the paving operation could be performed successfully. However, the connection strength of the specimen with an $18.7 \%$ overlap ratio was not satisfactory. Su stated that 35.9 and $27 \%$ overlap were acceptable. Thus, $33 \%$, which is between these two values, is acceptable. With an approximate $33 \%$ overlap ratio, several parts with acceptable deformation and connection strength were made in laboratories of the National Taipei University of Technology.9)

Once the ratio of line depth overlap is known, the ideal ratio of line width overlap can be calculated by eqs. (4) to (9). The ideal ratio of line width overlap must be small because the absorbed energy so the deformation will be minimized. It must also guarantee that every layer is $100 \%$ transformed and then the property of each layer will be uniform. All scanning patterns shown in Fig. 5 are drawn according to their ideal overlap ratios. Figure 6 can be used to illustrate how to determine the ideal ratio of line width overlap if ratio of line 
depth overlap is given. Introducing line depth $\left(D_{\mathrm{L}}\right)$, line width $\left(W_{\mathrm{L}}\right)$, and line depth overlap ratio $\left(R D_{\mathrm{O}}\right)$ into eqs. (4) to $(9)$, then the line width overlap ratio $\left(R W_{\mathrm{O}}\right)$ can be calculated as follows:

$$
\begin{aligned}
& \beta=\tan ^{-1}\left(2 D_{\mathrm{L}} / W_{\mathrm{L}}\right) \\
& r=W_{\mathrm{L}} / 4 \cos \beta \sin \beta \\
& \theta_{1}=\sin ^{-1}\left(W_{\mathrm{L}} / 2 r\right) \\
& \theta_{2}=\cos ^{-1}\left[\cos \theta_{1+} D_{\mathrm{L}}\left(1-R D_{\mathrm{O}}\right) / r\right] \\
& W_{\mathrm{O}}=W_{\mathrm{L}}-2 r \sin \theta_{2} \\
& R W_{\mathrm{O}}=W_{\mathrm{O}} / W_{\mathrm{L}}
\end{aligned}
$$

\subsubsection{Experiments for fabricating work pieces with ultra-thin layers}

To verify the feasibility of fabricating work pieces with ultra-thin layers, a multilayer experiment was conducted on the Scanner System; the thinnest layer was paved and a corresponding property transformation zone was produced by laser scanning. The thinnest layer thickness was determined by paving experiments (Sec. 2.3.1). The proper ratio of line depth overlap was around $33.3 \%$, as described in Sec. 2.3.2(2), so the line depth must be 1.5 times the thinnest layer thickness. The suitable laser power and scanning speed were the parameter sets for obtaining a line depth of 1.5 times the thinnest layer thickness and could be obtained from the laser line scanning experiment in Sec. 2.3.2(1). The line width produced by this parameter set also can be obtained by the same experiments. The proper ratio of line width overlap can be calculated by substituting the above-mentioned parameters into eqs. (4) to (9) in Sec. 2.3.2(2). The calculated ratio of line width overlap can then be multiplied by the line width to obtain an appropriate scanning space.

\section{Experimental Results}

\subsection{Results of paving experiments}

The results of paving experiments conducted on the Plotter System with 5 layer thicknesses and 11 paving speeds are shown in Table 2, indicating that a layer of $0.15 \mathrm{~mm}$ thickness could be paved with speeds between 17 and $30 \mathrm{~mm} / \mathrm{s}$. With a speed slower than $17 \mathrm{~mm} / \mathrm{s}$, say $13 \mathrm{~mm} / \mathrm{s}$, water infiltrated into the underneath dried layers, so that a bond between the fresh layer and the underneath layer was produced, and flow ability of the slurry was decreased. As a result, the lower layers were destroyed by the scraping.

Table 2 Results of layer paving experiments with different layer thicknesses and paving speeds on the Plotter System.

\begin{tabular}{lcccccccccccc}
\hline $\begin{array}{c}\text { Layer } \\
\begin{array}{c}\text { Thickness } \\
(\mathrm{mm})\end{array}\end{array}$ & 13 & 17 & 23 & 30 & 39 & 51 & 66 & 86 & 110 & 143 & 186 \\
\cline { 2 - 11 } & P & G & G & G & P & P & P & P & P & P & P \\
0.15 & P & G & G & G & G & P & P & P & P & P & P \\
0.1 & P & G & G & G & G & G & G & P & P & P & P \\
0.05 & P & G & G & G & G & G & G & G & G & G & P \\
0.025 & P & P & P & P & P & P & P & P & P & P & P \\
0.01 & P & P & P & P & &
\end{tabular}

Legend: $\mathrm{G}=$ Good $\quad \mathrm{P}=$ Poor

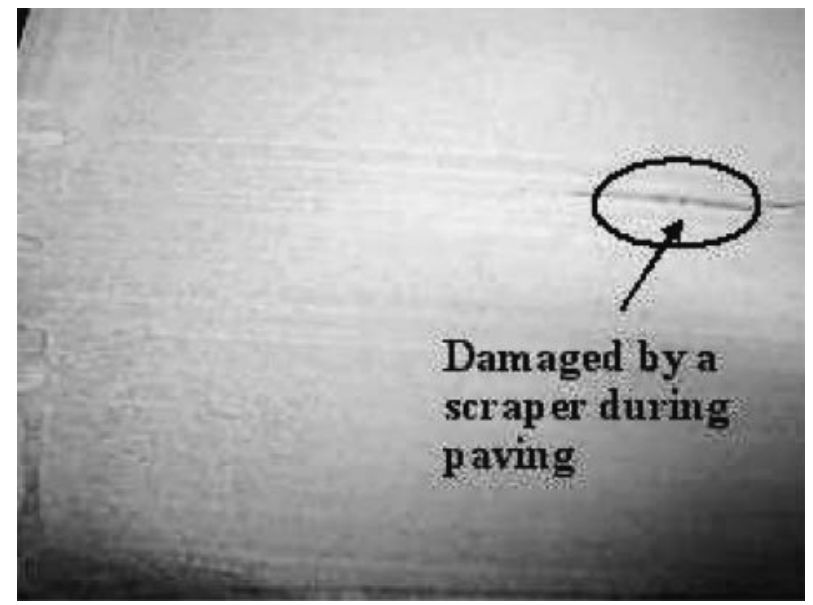

Fig. 7 Damaged surface of $0.01 \mathrm{~mm}$ thickness layer.

Therefore, in order to obtain a successful paving for all layer thicknesses, paving speed must be faster than $17 \mathrm{~mm} / \mathrm{s}$. On the other hand, paving with a high speed, the slurry might not be fed in time into the gap between the scraper and the work piece, producing an incomplete layer. For a $0.15 \mathrm{~mm}$ layer thickness, the paving speed could not be faster than $30 \mathrm{~mm} / \mathrm{s}$. For layer thicknesses $0.1,0.05$, and $0.025 \mathrm{~mm}$ the maximal paving speeds were 39,66 , and $143 \mathrm{~mm} / \mathrm{s}$, respectively. However, a layer with $0.01 \mathrm{~mm}$ thickness could not be made at any paving speed.

As a result, $0.025 \mathrm{~mm}$ is the thinnest thickness that can be paved on the Plotter System; the maximum paving speed was $143 \mathrm{~mm} / \mathrm{s}$, although a better surface was obtained with a paving speed of $110 \mathrm{~mm} / \mathrm{s}$.

Similar paving experiments conducted on Scanner System showed that the minimal layer thickness was $0.015 \mathrm{~mm}$. Figure 7 indicates a $0.01 \mathrm{~mm}$ thick layer, which was incomplete because some ceramic particles were larger than the layer thickness and were scraped into the layer underneath. Accordingly, if the particle of the ceramic were sieved and controlled to be smaller than $0.01 \mathrm{~mm}$, the desired $0.01 \mathrm{~mm}$ layer could be made successfully.

\subsection{Results of laser scanning experiments}

\subsubsection{Relationship between geometric dimensions and laser scanning parameters}

Figure 8 is the cross section of the lineal property transformation zone produced on Plotter System with a relatively high energy density of $0.39 \mathrm{~J} / \mathrm{mm}^{2}$. The scanned line was broken and then bonded onto a metal fixture for SEM inspection. Figure 9 schematically presents the related dimensions in the property transformation zone and the boundary lines of depression zone, fusing zone and sintering zone. From Fig. 8, the measured line width (CW2) is $0.35 \mathrm{~mm}$, line depth $(\mathrm{Cd} 2)$ is $0.112 \mathrm{~mm}$, and the depth of depression zone is $(\mathrm{Cd} 0) 0.04 \mathrm{~mm}$. Due to the laser irradiation, the temperature of the work piece surface increased rapidly, and heat was transferred inward from the surface, forming arc-shaped isotherms. The fusing isotherm of silica and fusing isotherm of volcanic clay were notable. The silica particles and volcano clay particles above the fusing isotherm of silica were all melted, and a very small 


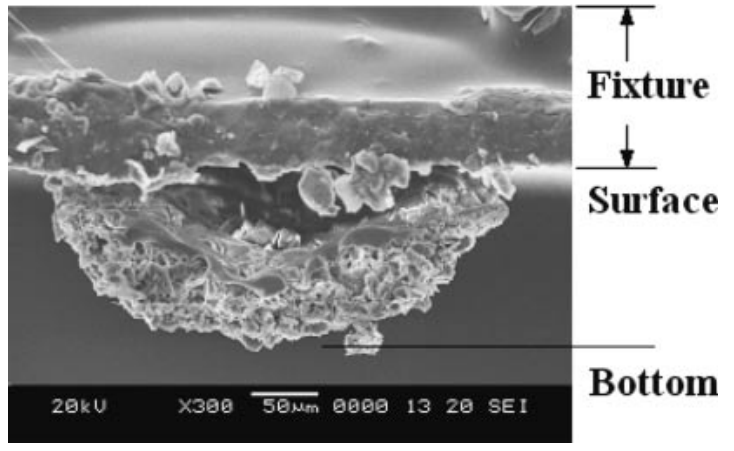

Fig. 8 Cross section of the line property transformation zone produced by energy density of $0.39 \mathrm{~J} / \mathrm{mm}^{2}$.

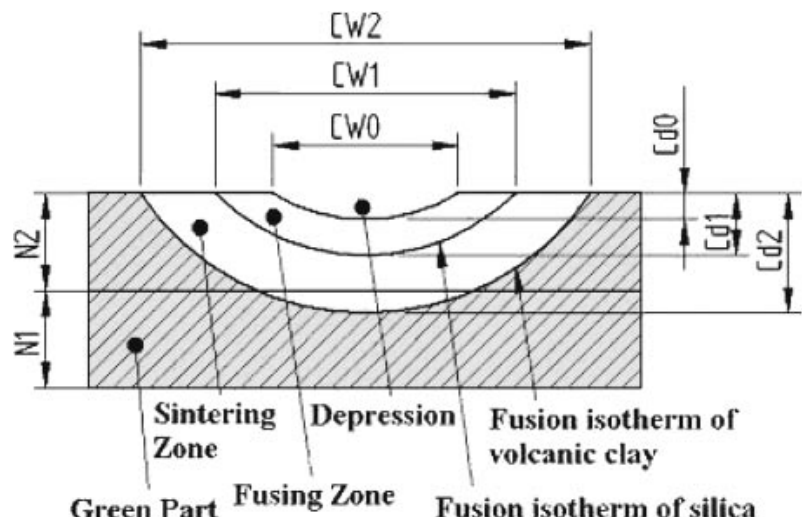

portion of the liquid material was evaporated rapidly, so a substantial impulse was transmitted to the liquid. A portion of the liquid material was blown away by the gaseous material. Because material leave the surface not only through evaporation, but also in the liquid state at a relatively high velocity, ${ }^{12)}$ a rather extensive depression was formed. The portion between the melting isotherms of silica and volcanic clay was the sintering zone, where the melted volcanic clay connected the solid silica particles. According to oven experiments, after being heated to a temperature above $1200^{\circ} \mathrm{C}$, a green part was transformed to a sintered part that could not be dissolved in the $\mathrm{NaOH}$ water solution. In addition, $1200^{\circ} \mathrm{C}$ was found to be the melting point of the volcanic clay used in this experiment.

After scanning, the scanned work piece was placed in a dissolving agent such as the $\mathrm{NaOH}$ water solution to clean off the green part under the fusing isotherm of the volcanic clay; however, the fusing zone and sintering zone could stay in the original form because they were basic-resistant.

The surface of a work piece that is manufactured by overlapping the lines with a deep depression, such as the one shown in Fig. 8, will be very rough. In contrast, low temperature scanning can eliminate the depression and obtain a sooth surface.

Figure 10 is the cross section of the overlapped property transformation zones produced by a low temperature lineal scanning with energy density $0.17 \mathrm{~J} / \mathrm{mm}^{2}$ on the Plotter System. This layer consisted of several overlapping line with

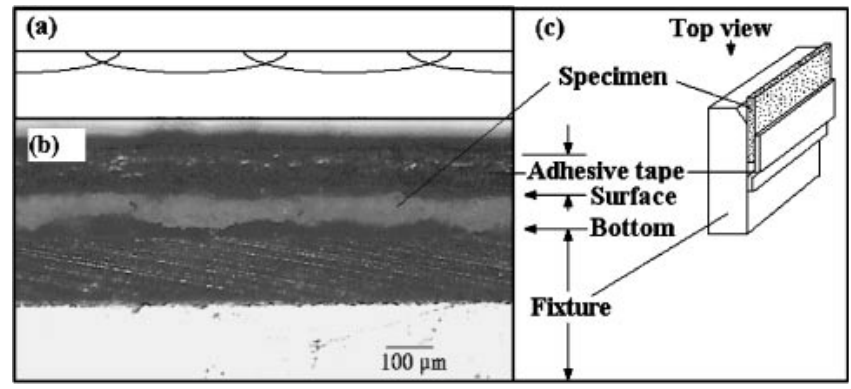

Fig. 10 Property transformation zone produced by low temperature scanning (Energy density $0.17 \mathrm{~J} / \mathrm{mm}^{2}$ ).

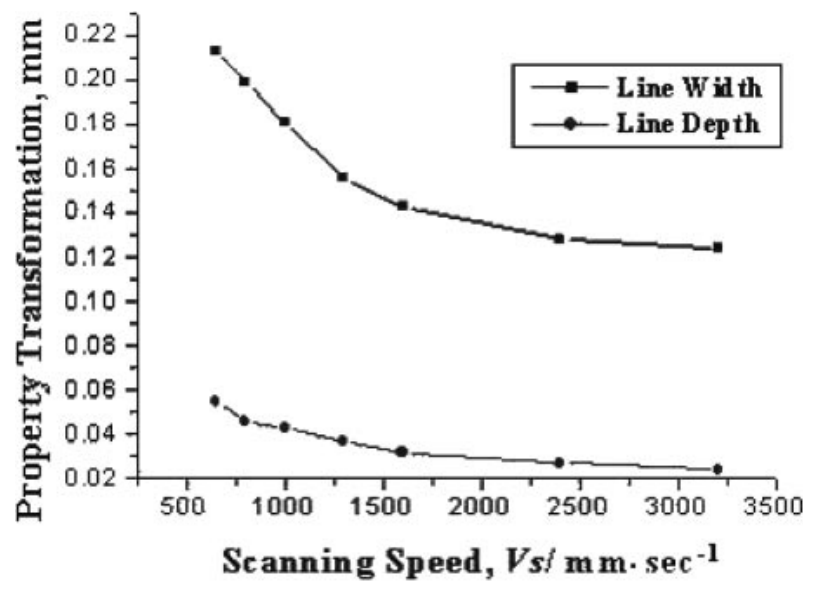

Fig. 11 Effect of scanning speed on line depth and line width.

$0.086 \mathrm{~mm}$ line depth and $0.661 \mathrm{~mm}$ line width. Line space was $0.4 \mathrm{~mm}$, corresponding to $39.5 \%$ overlap ratio. On the top of this layer there were no depressions or fusing zones, so its surface was even, whereas its bottom had an overlapping arc-shaped boundary.

The dimensions of the property transformation zones produced by low temperature scanning on the Scanner System with seven scanning speeds faster than $300 \mathrm{~mm} / \mathrm{s}$ are presented in Fig. 11. The laser power was kept to $33 \mathrm{~W}$ and the scanning speed increased from 650 to $3200 \mathrm{~mm} / \mathrm{s}$, the transformed line width and line depth produced by laser sintering were reduced continuously. The line width was decreased from 0.213 to $0.124 \mathrm{~mm}$ and the line depth was decreased from 0.055 to $0.024 \mathrm{~mm}$. The experimental data suggest an approximately inverse relationship between the line depth and square root of the scanning speed:

$$
D_{\mathrm{L}}=0.0602\left(V_{\mathrm{s}}\right)^{-0.415}
$$

\subsubsection{Work piece with thinnest layer thickness}

The thinnest layer made by the Scanner System was $0.015 \mathrm{~mm}$, so combined with $3200 \mathrm{~mm} / \mathrm{s}$ scanning speed and $33 \mathrm{~W}$ laser power a $0.024 \mathrm{~mm}$ transformed line depth could be obtained. Its corresponding line depth overlap ratio was $37.5 \%[(0.024-0.015 \mathrm{~mm}) / 0.024 \mathrm{~mm}]$. Substituting these data and $0.124 \mathrm{~mm}$ line width taken from Fig. 11 into eqs. (4) to (9), a proper ratio of line width overlap $36 \%$ was found and the corresponding scanning space was $0.079 \mathrm{~mm}$. These parameters were used on the Scanner System to manufacture 


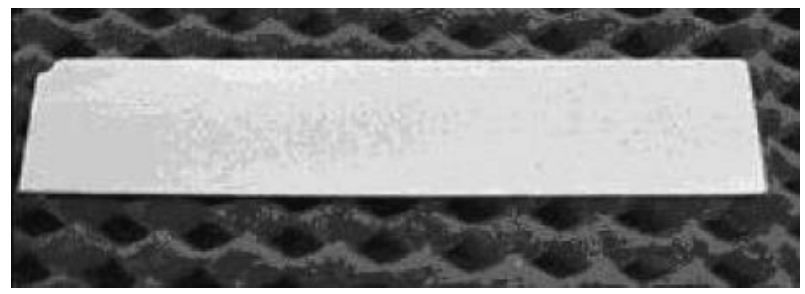

Fig. 12 Work piece fabricated with layer thickness of $0.015 \mathrm{~mm}$.

a 20 layer work piece by laser scanning. Figure 12 shows a photograph of this work piece to verify that using above parameters a work piece with $0.015 \mathrm{~mm}$ layer thickness can be made safely.

\section{Discussion}

Making a work piece with ultra-thin layers $(0.015 \mathrm{~mm})$ can be achieved by CLS. This is thinner than the layers previously made by powder-based processes. This section discusses the significant parameters which influence the layer thickness, the methods which can decrease upward deformation and the reasons why CLS can build ultra-thin layers; finally, the possible thinnest layer thickness built by CLS will be estimated.

\subsection{Significant parameters influencing layer thickness}

A work piece made by Rapid Prototyping is assembled layer by layer. For the CLS process, there are three conditions for successful layer manufacturing: (1) the finished portion should not be damaged by a scraper during next paving (see Fig. 1 step 2); (2) connection must be established between layers during laser scanning (see Fig. 1 step 5), and (3) the property transformation zone must be strong enough to resist the foreign force during the removal of the green portion (see Fig. 1 step 7).

Fulfilling theses three conditions means that the process is safe, and with thinner layers there is less process safety. In case of constant process error, if the layer thickness is decreased, it will be easier for the values of the parameters to be out of the completely safe zone. Therefore, it is essential to decrease the feasible layer thickness by studying the parameters which influence the process safety.

Before building the first layer of the work piece, a sacrifice layer with approximate $1 \mathrm{~mm}$ thickness must be constructed. The paving of the sacrifice layer and first layer involve only layer paving and drying. After the paving of the first layer, the additional step of laser scanning is necessary. The paving for the second and successive layers is somewhat different from the previous paving since they pave a slurry layer over a layer which has been scanned by laser. The effects of laser scanning, such as deformation of the scanned layer, must be considered in this somewhat complex layer making process. If the amount of deformation is larger than a layer thickness, then the work piece will be damaged by the scraper. Sections below discuss the relationship between the parameters and layer thickness when laser scanning is involved. The influential parameters will be divided into parameters related to paving and to laser scanning.

\subsubsection{Paving related parameters}

The influence parameters of layer thickness related to paving are as following:

(1) Particle size of the powder: With smaller particle size, thinner layers are feasible. Clearly, the particle size of the powder limits the smallest feasible layer thickness. If the particle size of the powder is larger than the layer thickness, the lower green layer could be damaged during the scraping operation. Therefore, the particle size of the powder must be kept smaller than the layer thickness.

(2) Paving force carrying capacity of paved layer: With larger paving force carrying capacity of the paved layer, thinner layers are feasible. Here the paving force occurs when paving successive slurry layers by a scraper. This force can be calculated by Newton's law, eq. (11). ${ }^{13)}$

$$
\begin{aligned}
& F=\mu(U / h) A \\
& F=C / h=F_{\text {resist }}
\end{aligned}
$$

$F$ : paving force

$\mu$ : viscosity of slurry

$U$ : paving velocity

$h$ : slurry thickness

$A$ : paving area

$C:$ constant $=\mu(U) A$

$F_{\text {resist }}$ : Paving Force Carrying Capacity

The viscosity of the slurry $(\mu)$, paving velocity $(U)$, and paving area $(A)$ in eq. (11) can not be arbitrarily decreased and they are normally maintained as constants. Thus, a small layer thickness $(h)$ leads to a larger paving force $(F)$. This paving force must be withstood by the lower layer, which can be called the paving force carrying capacity. If the layer thickness is reduced from the commercially used $0.1 \mathrm{~mm}$ down to $0.01 \mathrm{~mm}$, the paving force is ten times greater. Therefore, if an ultrathin layer thickness is needed, constructing solid support is necessary to resist the accompanying large paving force. For example, SLA builds solid supports under overhanging structures, so its layer thickness can reach $0.05 \mathrm{~mm}$. On the contrary, processes such as 3DP and SLS employ powder supports which can not stand up to the tangential paving force, so their ability to pave a very thin layer is limited.

\subsubsection{Scanning related parameters}

The parameters of layer thickness related to laser scanning are stated as following:

(1) Upward deformation of the property transformation zone: The upward deformation must be smaller than the feasible layer thickness. Figure 13 shows the schematic of a T shaped part made by SLM. ${ }^{14)}$ Because this part was built without support, after manufacturing three

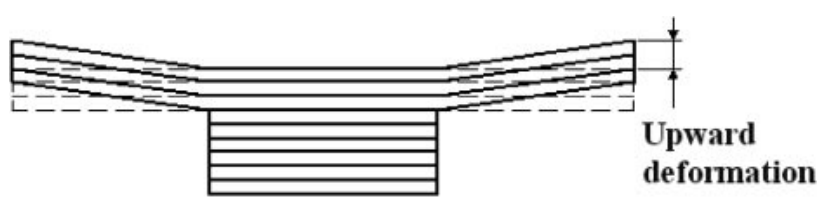

Fig. 13 Upward deformation. 
layers of the overhanging portion, the upward deformation shown in the Fig. 13 was larger than a layer thickness, so that the scraper could not be moved over the part. If the upward deformation of the property transformation zone is larger than the thickness of a green layer, the just-finished layer will be damaged by the next scraping operation. As a result, in order to safely pave layers above the already scanned area, the upward deformation must be smaller than the thickness of one green layer.

(2) Anti-fracture strength of the property transformation zone: With higher the anti-fracture strength, there can be thinner layers. When the previously mentioned demand, that property transformation zone depth must be equal to 1.5 times layer thickness, is applied to a very thin layer, the resulting property transformation zone depth is also very small; this small depth clearly has smaller cleaning force carrying capacity than a large depth when the finished part is separated from the green portion by a water jet. In order to fulfill the demand, that the property transformation zone must withstand the force during green portion removal (Fig. 1 step 7), a thin layer must have a greater anti-fracture strength than a thick layer.

\subsection{Method to decrease upward deformation}

It is frequently emphasized that decreasing upward deformation is essential to process safety. The meaningful property transformation zone depth is between 1.5 times to 2.0 times of the layer thickness. So, the key point to improving process safety is to decrease the upward deformation of the property transformation zone, which has a thickness of 2.0 times layer thickness. The two methods to decrease upward deformation are as follows:

(1) Reducing working temperature: For the same purpose of producing a property transformation zone that is 2.0 times layer thickness, if the process works at a lower working temperature, then the energy density necessary for property transformation will be decreased, lower thermal stress will be induced, and so the upward deformation of the so produced property transformation zone will be diminished.

Experimental results indicate that the volcanic clay fuses at $1200^{\circ} \mathrm{C}$ and silica powder fuses at $1800^{\circ} \mathrm{C}$. The CLF process is based on fusion of the silica powder, so the working temperature of CLF is above $1800^{\circ} \mathrm{C}$. Also some other fusion-based SLS processes, i.e. ceramic fusion by Wirtz, ${ }^{15)}$ metal melting by Meiners, ${ }^{16)}$ work at a temperature above the melt point. CLS is based on liquid sintering, in which only the added volcanic clay fuses, while the silica powder remains in solid state; therefore, CLS has a lower working temperature, above $1200^{\circ} \mathrm{C}$. Because the CLS process needs less energy density than fusion-based processes, CLS has the advantage of decreasing deformation.

(2) Building solid support: Solid support can effectively reduce the upward deformation of the property transformation zone. Processes working at high temperature, such as metal melting by Meiners, ${ }^{14)}$ shown in Fig. 13, the powder support could not prevent upward deforma- tion, after building three layers the deformation became so large that the scraper touched the deformed lower layer. Once the solid supports were built, the work piece could be finished because there was no excessive deformation. Although CLF works at temperatures over $1800^{\circ} \mathrm{C}$, its inherent solid green portion is an effective solid support, which offers enough strength to prevent transformed portion from upward deformation caused by thermal stress. Haung reported that the flatness of specimens with solid support was increased to 0.01$0.05 \mathrm{~mm}$ after support removal; ${ }^{17)}$ this experiment suggested that solid support could effectively resist the internal stress and prevent deformation.

\subsection{Evaluating the thinnest layer thickness}

The reasons why CLS can build ultra-thin layers (0.015 $\mathrm{mm}$ ) are: (1) the powder particle size was under 15 micrometers; the already paved layer will not be scratched by the large particles, which might be pushed by the scraper; (2) its inherent solid green portion provides solid support to resist the paving force induced by successive paving operations and to prevent excessive upward deformation induced by laser scanning; (3) its lowest working temperature was decreased from $1800^{\circ} \mathrm{C}$ of CLF to $1200^{\circ} \mathrm{C}$.

Evaluating the CLS process according to sections 4.1 and section 4.2 indicates that CLS has potential to build ultra-thin layers. Considering the paving parameters, there is no limitation for CLS to pave and dry a thin layer because the supply of sub-micrometer powder presents no problems and the solid green support can sufficiently withstand the paving force caused by successive paving. A real limitation to the feasible thinnest layer is the repetition accuracy of $Z$-axis. A commercial tape casting machine made by Keko-equipment can fabricate $5 \mu \mathrm{m}$ layers. ${ }^{18)}$ Hence $5 \mu \mathrm{m}$ is a realizable layer thickness in regard to a simple layer paving.

Regarding to the laser scanning parameters, the CLS process has an inherent solid green portion support to prevent the work piece from an excessive upward deformation. Although the working temperature of CLS is over $1200^{\circ} \mathrm{C}$, the suitable ratio of line width overlap and ratio of line depth overlap could be found to successfully build a work piece with ultra-thin layers. This paper shows that CLS can make a simple work piece with a $0.024 \mathrm{~mm}$ property transformation depth if the scanning speed is $3200 \mathrm{~mm} / \mathrm{s}$ and laser power is $33 \mathrm{~W}$. In order to achieve a $0.005 \mathrm{~mm}$ layer thickness, building a $0.0075 \mathrm{~mm}$ depth of property transformation zone is essential. Apparently, with a very fast speed, say $28000 \mathrm{~mm} / \mathrm{s}$, according to the equation: $D_{\mathrm{L}}=$ $0.0602\left(V_{\mathrm{s}}\right)^{-0.415}$ this thin thickness perhaps can be made, if the scanner can be operated accurately at this speed. Alternatively, it may also be possible to make it by using a lower laser power and then a scanning speed lower than $28000 \mathrm{~mm} / \mathrm{s}$. However, the ultimate challenge is that very thin layers with a small thickness like $0.0075 \mathrm{~mm}$ should have sufficient cleaning force carrying capacity to maintain its integrity during the green portion removal. As a conclusion, it is not certain that layers as thin as $0.005 \mathrm{~mm}$ can be built; and this needs further study. 


\section{Conclusions}

Previously, the thinnest feasible layer thickness for RP ceramic work pieces built by CLF was $0.1 \mathrm{~mm}$. This paper presents a new process, CLS, which can pave layers with $0.015 \mathrm{~mm}$ thickness, the thinnest layer ever made by powderbased process. CLS works according to liquid sintering with a lower working temperature, and can safely make a work piece with a $0.024 \mathrm{~mm}$ depth of property transformation zone. The most important reasons why CLS can build ultrathin layers are that (1) because it paves layers with a slurry, so very fine powder can be processed; (2) after drying the slurry, a solid green support is formed that can withstand the paving force during successive paving operations and prevent excessive upward deformation induced by laser scanning; and (3) its lowest working temperature was decreased from $1800^{\circ} \mathrm{C}$ of $\mathrm{CLF}$ to $1200^{\circ} \mathrm{C}$.

\section{Acknowledgements}

The author would like to thank Tai-Chen Chen for his executing some of the laser scanning experiments and HsiaoChuan Yen for his drafting. This work was supported by the National Science Council in Taiwan under project no. NSC 94-2212-E-027-011.

\section{REFERENCES}

1) Milwaukee Precision Casting Corp.: Technical report, http://www. milwaukeeprec.com, Milwaukee. WI. USA.

2) H. H. Tang, H. C. Yen, S. M. Su and Z. Y. Lin: Proc. The 15th Solid
Freeform Fabrication Symposium, ed. by D. L. Bourell, (The U. of Texas at Austin, Texas, USA, 2004) pp. 268-280.

3) Shellabear, A. Danzig, M. Heugel, J. Kotila and O. Nyrhilä: SME Member Newsletter Rapid prototyping 9 (2003).

4) C. K. Chua and K. F. Leong: Rapid Prototyping, (John Wiley \& Sons, Inc., Singapore 1997) pp. 29-149.

5) MCP: The MCP Realizer-Selective Laser Melting, http://www. Mcp-group.com.

6) H. H. Tang: Method for rapid forming of a ceramic work piece, U.S. Patent no. 6217816, (2001).

7) H. H. Tang: RP Journal 8 (2002) 284-289.

8) H. H. Tang and H. C. Yen: Mater. Trans. 45 (2004) 2744-2751.

9) S. M. Su: Fabricating Ceramic Shell Mold for Precision Casting by Ceramic Laser Fusion, MS Thesis, (NTUT, Taipei, Taiwan, 2004) pp. 77-80.

10) J. S. Reed: Principles of ceramics processing, (New York, John Wiley \& Sons, 1994) pp. 395-397.

11) S. M. Su: Fabricating Ceramic Shell Mold for Precision Casting by Ceramic Laser Fusion, MS Thesis, (NTUT, Taipei, Taiwan, 2004) pp. 61-66.

12) Nontraditional Machining Processes, second edition, Ed. by E. J. Weller (SME, Dearborn, MI, USA) pp. 144-145.

13) M. F. Spotts: Design of Machine elements, (Prentice-Hall, New Jersey, 1985) pp. 382-383.

14) W. Meiners: Direktes Selektives Laser Sintern einkomponentiger metallischer Werkstoffe, Dissertation, (RWTH Aachen, 1999) pp. 8586.

15) H. Wirtz: Selektives Lasersintern von Keramikformschalen für Giessanwendungen, Dissertation, (RWTH Aachen, 2000) pp. 98-100.

16) W. Meiners: Direktes Selektives Laser Sintern einkomponentiger metallischer Werkstoffe, Dissertation, (RWTH Aachen, 1999) pp. 2933.

17) S. H. Haung: The Process improvement and accuracy analysis of Ceramic Laser Fusion, MS Thesis, (NTUT, Taipei, Taiwan, 2002) pp. 73-74.

18) Keko-equipment: Automatic Tape Casting Machines suitable for Green Ceramic, http://www. Keko-equipment.com, Zuzemberk, Slovenia. 